\title{
MACHINING PERFORMANCE OF ALUMINUM ALLOY 6061-T6 ON SURFACE FINISH USING MINIMUM QUANTITY LUBRICATION
}

\author{
M.S. Najiha ${ }^{1}$, M.M. Rahman ${ }^{1 *}$ and K. Kadirgama ${ }^{1}$ \\ ${ }^{1}$ Faculty of Mechanical Engineering, Universiti Malaysia Pahang \\ 26600 Pekan, Kuantan, Pahang, Malaysia \\ *Email: Mustafizur@ump.edu.my \\ Phone: +6094246239; Fax: +6094246222
}

\begin{abstract}
This paper presents an experimental investigation of coated carbide cutting tool performance on the surface roughness of aluminum alloy 6061-T6 machining through end mill processes using the minimum quantity lubrication technique. Process parameters including the cutting speed, depth of cut and feed rate are selected. The central composite design method is used for design of experiments. Two types of coated carbide tool are used in this experiment - an uncoated tungsten carbide insert and TiAlN+TiN-coated carbide insert. The analysis of variance method is utilized to validate the experimental data and to check for adequacy. The response surface method was used to develop the mathematical models and to optimize the machining parameters. Second-order regression models are developed based on the surface roughness results. It is observed that the surface roughness depends significantly on depth of cut and feed rate, followed by spindle speed for both the coated carbide inserts. The performance of the dual-layered coating of TiAlN+TiN is competent as compared to the surface quality obtained with TIAIN-coated inserts. The results can be used as an example of MQL applied to the machining of aluminum alloys, providing economic advantages in terms of reduced lubricant costs and better machinability.
\end{abstract}

Keywords: Coated carbide inserts; aluminum alloy 6061-T6; surface roughness; feed rate; MQL flow rate.

\section{INTRODUCTION}

Keeping in view all the elements of sustainable manufacturing, the machining industry is continually looking for methods and techniques for increased machining process performance with cost-effectiveness. The global environmental concerns, which has pressurized industry to reduce production costs, has directed the industry to give careful thought to the role of the conventional metal-working fluids used in machining processes. Minimum quantity lubrication (MQL) is a new sustainable practice of cooling and lubrication in machining that has resulted in the optimized use of metalworking fluids [1-3]. The goal of MQL is to produce parts using an optimized minimum quantity of metal-working fluids so that the workpiece, chips and environment remain dry after cutting. MQL has proved an effective near-dry machining technique from the viewpoint of cost, environmental and human health issues. According to research, the cost of using metal-working fluids may range from 7 to $17 \%$ of the total cost of the manufactured workpiece [4]. This cost is very significant, so by applying the MQL technique, a notable decline in machining costs can be achieved just by optimizing the 
quantity of lubricant used in machining. MQL is a sustainable manufacturing technique that is harmless for the environment, the machinist and is cost-effective [5]. Minimization of metal-working fluids is a gage of sustainable manufacturing. MQL has proved to provide several advantages: the chips, workpiece and tool holder have little left-over cooling and lubricating fluid and therefore their cleaning and material recycling is easier and inexpensive; also the workplace is not contaminated, thus assisting in monitoring the cutting operation at the floor. MQL is an achievementoriented technology, which replaces conventional lubrication techniques and takes over the lubrication task, assisting in sustainable development in mechanical manufacturing processes. A methodology was proposed by Shao, Kibira [6] that uses a virtual model of a machining system to analyze the environmental impact of the process. The objective of the simulation system, scope, model elements, and its input and output requirements are discussed. This approach allows us to assess the environmental impact in a virtual environment using real-world data, specification data, and simulation data as input and providing a platform to evaluate the different options for optimal decision-making.

A lot of research has been conducted in the field of minimum quantity lubrication as a sustainable manufacturing technique. This is because the metal-working fluids used as cooling and lubricating media in machining operations create many concerns related to personal health and safety as well as a significant increase in the cost of machining operations. But the data available is mostly limited to the effects of minimum quantity lubrication on machining parameters such as surface roughness, tool wear etc. The performance of the milling process depends largely on how fast the machine can cut the workpiece, meaning that even a slight change in a machining element, such as implementing a suitable coating on the cutting tool, could improve the machinability of a material [7]. High productivity needs a high rate of metal removal, so it will reduce the manufacturing cost and operation time. The large amount of cutting fluid contains potentially damaging or environmentally harmful chemical elements that can expose operators to skin and lung disease as well as air pollution [8]. The minimal quantity lubrication used is compared to another cutting fluid. MQL in an end milling process is very effective according to Lacalle, Lamikiz [9] and MQL can reach the tool face more easily in milling operations compared with other cutting operations. AA6061T6 is a more suitable choice due to its cost-efficiency [10] and the economic aspect has always been important when it comes to mass production [11]. Ghani, Choudhury [12] reported that the coating typically reduced the coefficient of friction between the cutting tool and the workpiece, eventually reducing the tool wear. Eventually, sudden failure of cutting tools leads to loss of productivity, rejection of parts and consequential economic losses. A coated carbide tool is considered in this study to evaluate the performance of the machining process depending on tool wear or tool life. The objectives of this study are to experimentally investigate the machining characteristics of aluminum alloy in end milling processes for MQL techniques and to investigate the performance of a coated carbide cutting tool on the surface finish when using the MQL method.

\section{METHODS AND MATERIALS}

\section{Workpiece Material}

Aluminium alloy 6061-T6 has been selected for the experimental investigation. AA6061-T6 aluminum alloy (Al-Mg-Si alloy) has gained widespread acceptance in the fabrication of lightweight structures requiring a high strength-to-weight ratio and good 
corrosion resistance [13]. The chemical composition in mass \% of base metal (BMs) AA6061-T6 is $0.92 \mathrm{Mg}, 0.68 \mathrm{Si}, 0.43 \mathrm{Cu}, 0.33 \mathrm{Fe}, 0.013 \mathrm{Mn}, 0.01 \mathrm{Ti}, 0.01 \mathrm{Zn}$, Al balance [14]. According to Zhang, Wu [15], AA6061-T6 is widely used in numerous engineering applications including transport and construction, where superior mechanical properties such as tensile strength and hardness are essentially required. There are many instances of the use of this kind of aluminum. It can be used for a variety of interior parts in cars, in railway carriages, pipelines, furniture or in trucks. The inherent corrosion resistance of these alloys and their filler metals is also excellent. Table 1 shows the chemical composition of aluminum alloy AA6061-T6. As can be seen, the aluminum mostly consists of magnesium which is $4.98 \%$, besides the main component which is the base metal, 6061. Silicon is also present in this alloy. An aluminum alloy workpiece of size $100 \mathrm{~mm} \times 100 \mathrm{~mm} \times 30 \mathrm{~mm}$ is used for the study, as shown in Figure 1.

Table 1. Chemical compositions (wt\%) of AA6061-T6 [14].

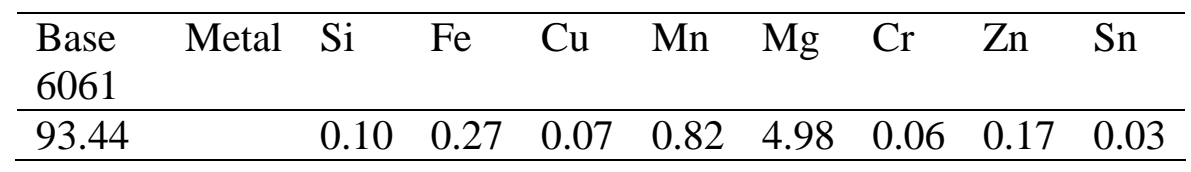

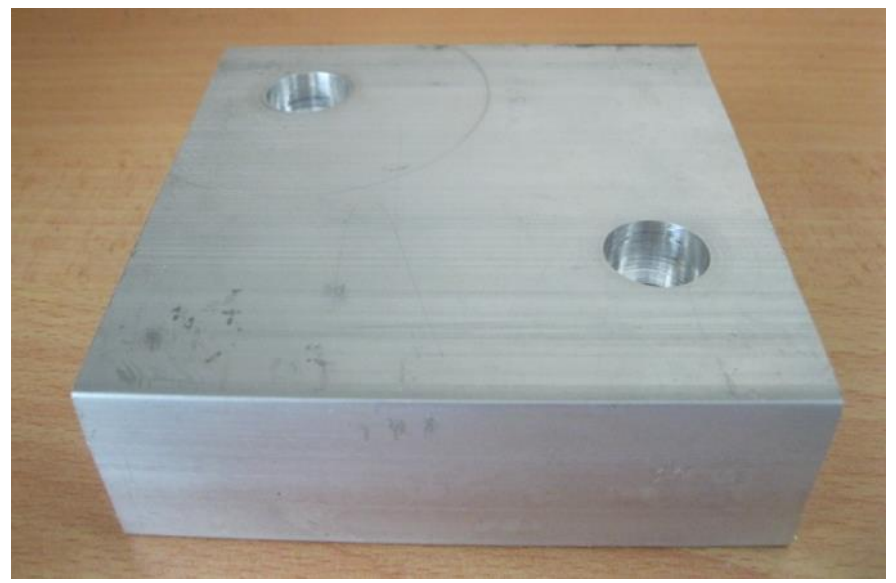

Figure 1. Workpiece aluminum alloy 6061-T6.

\section{Cutting Tool Materials}

The cutting tools used for this experiment are uncoated WC-Co insert and TiAlN+TiN coated carbide end mill inserts. Tool machining is the radical process of friction and wear. Tool wear during cutting not only decreases the service life of cutting tools, but also leads to increased roughness of the cutting surfaces of workpieces [16]. According to Ghani, Choudhury [12], coated carbide is suitable for machining because it is possible to employ the carbide- and nitride-based tool materials at cutting speeds that are so low that mechanical wear predominates. In addition to that, these tool materials are limited by chemical stability, where the tool material dissolves into the flowing chip. Table 2 shows the composition of the coated and uncoated carbide inserts. It can be observed that there is, although small, a significant difference in grain size between the coated and uncoated carbide inserts. However, the composition of the two is very similar except for the slight difference in the quantity of tungsten carbide in the inserts. 
Table 2. Composition of the coated and uncoated carbide inserts $[17,18]$.

\begin{tabular}{llll}
\hline Type of carbide & Composition & Coating & Grain size \\
\hline Coated carbide & $6 \%$ of Co, $4 \%$ carbide,90\% WC & PVD & $4 \mu \mathrm{m}$ \\
& & TiA1N, TiN & \\
Uncoated carbide & $6 \% \mathrm{Co}, 94 \% \mathrm{WC}$ & - & $1 \mu \mathrm{m}$ \\
\hline
\end{tabular}

\section{Experimental Design}

In high-speed machining, the range of values of spindle speed, feed rate, depth of cut (DOC) and flow rate need to be determined in order to proceed with the experiment. After analyzing the previous literature and machine specifications and limitations, the range of parameters selected for machining is shown in Table 3.

Table 3. Design of experiments for machining.

\begin{tabular}{|c|c|c|c|c|c|}
\hline & $\begin{array}{l}\text { Exp. } \\
\text { No. }\end{array}$ & $\begin{array}{c}\text { Cutting } \\
\text { speed } \\
(\mathrm{m} / \mathrm{s})\end{array}$ & $\begin{array}{l}\text { Feed rate } \\
(\mathrm{mm} / \mathrm{rev})\end{array}$ & $\begin{array}{l}\text { Depth } \\
\text { of cut } \\
(\mathrm{mm})\end{array}$ & $\begin{array}{c}\text { Flow } \\
\text { rate } \\
\text { (ml/min) }\end{array}$ \\
\hline Workpiece & 1 & 5252 & 379 & 2.00 & 0.6525 \\
\hline \multirow[t]{3}{*}{$\mathrm{A}$} & 2 & 5300 & 318 & 1.00 & 0.48 \\
\hline & 3 & 5300 & 318 & 1.00 & 0.825 \\
\hline & 4 & 5300 & 318 & 3.00 & 0.48 \\
\hline Workpiece & 5 & 5300 & 318 & 3.00 & 0.825 \\
\hline \multirow[t]{3}{*}{ B } & 6 & 5300 & 440 & 1.00 & 0.48 \\
\hline & 7 & 5300 & 440 & 1.00 & 0.825 \\
\hline & 8 & 5300 & 440 & 3.00 & 0.48 \\
\hline Workpiece & 9 & 5300 & 440 & 3.00 & 0.825 \\
\hline \multirow[t]{3}{*}{$\mathrm{C}$} & 10 & 5400 & 288 & 2.00 & 0.6525 \\
\hline & 11 & 5400 & 379 & 0.52 & 0.6525 \\
\hline & 12 & 5400 & 379 & 2.00 & 0.39 \\
\hline Workpiece & 13 & 5400 & 379 & 2.00 & 0.6525 \\
\hline \multirow[t]{3}{*}{$\mathrm{D}$} & 14 & 5400 & 379 & 2.00 & 0.6525 \\
\hline & 15 & 5400 & 379 & 2.00 & 0.9 \\
\hline & 16 & 5400 & 379 & 3.48 & 0.6525 \\
\hline Workpiece & 17 & 5400 & 469 & 2.00 & 0.6525 \\
\hline \multirow[t]{3}{*}{$\mathrm{E}$} & 18 & 5500 & 318 & 1.00 & 0.48 \\
\hline & 19 & 5500 & 318 & 1.00 & 0.825 \\
\hline & 20 & 5500 & 318 & 3.00 & 0.48 \\
\hline Workpiece & 21 & 5500 & 318 & 3.00 & 0.825 \\
\hline \multirow[t]{3}{*}{$\mathrm{F}$} & 22 & 5500 & 440 & 1.00 & 0.48 \\
\hline & 23 & 5500 & 440 & 1.00 & 0.825 \\
\hline & 24 & 5500 & 440 & 3.00 & 0.48 \\
\hline Workpiece & 25 & 5500 & 440 & 3.00 & 0.825 \\
\hline $\mathrm{G}$ & 26 & 5548 & 379 & 2.00 & 0.6525 \\
\hline
\end{tabular}




\section{Measurement of Surface Roughness}

After the experiment has been done, one of the output parameters that needs to be measured is surface roughness. The surface roughness was tested by using a portable roughness tester (perthometer). The perthometer is a device with high sensitivity that is able to find very small differences in surface roughness. Figure 2 shows the Mahr perthometer. Prior to measurement, the workpiece should be completely clean of any impurities so that the data will be pure and accurate.

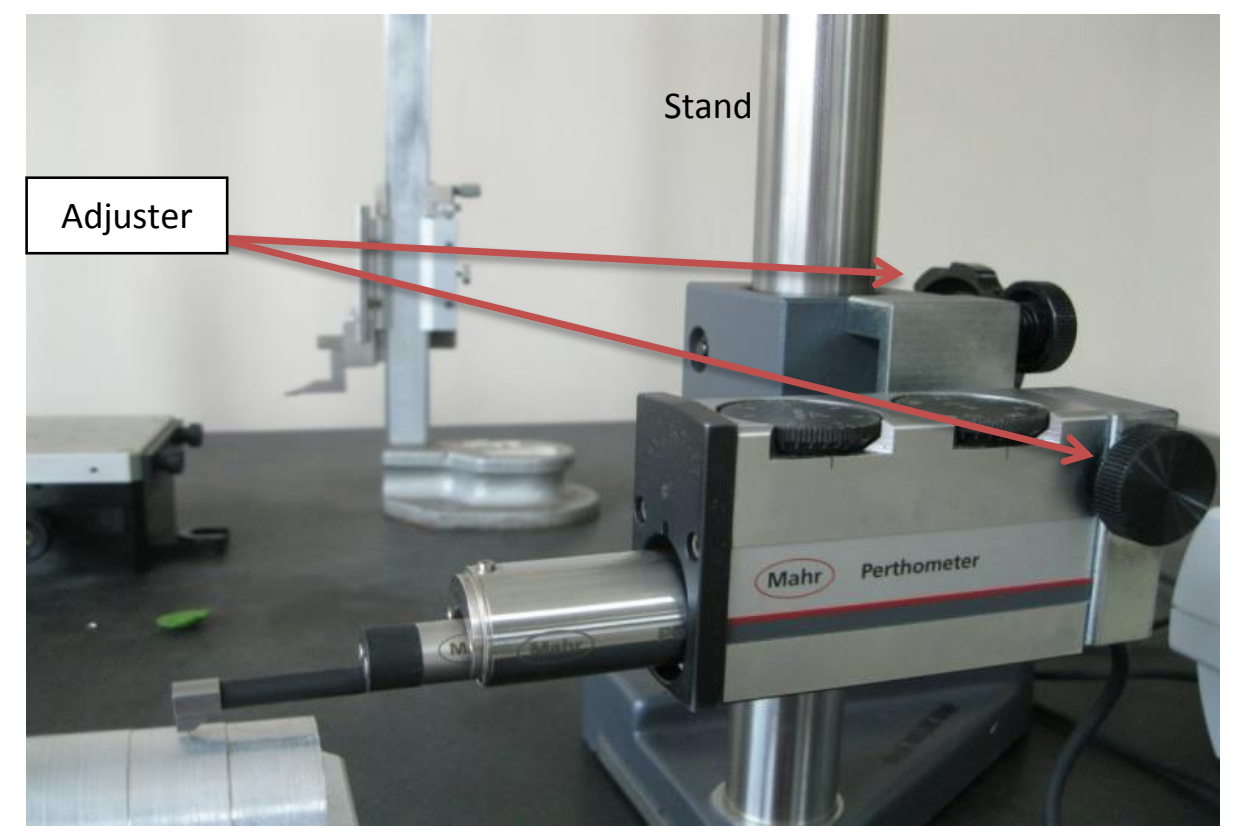

Figure 2. Surface roughness measuring device.

\section{Cutting Fluid}

For the investigation, the experiment was done with both minimum quantity and flooded lubrication. MQL is reported to be a good choice for milling operations. [19] conducted multiple experiments and concluded that the cutting performance of MQL machining is better than that of dry and conventional machining with a flooded cutting fluid supply because MQL has the major advantage of reducing the cutting temperature and thus enhancing the chip-tool interaction. Besides, surface finishes are also improved mainly due to the reduction of wear and damage at the tool tip by the application of MQL. In this study, UNIST Coolube oil is used as the MQL medium and is delivered to the cutting zone using a UNIST mist dispenser unit, as shown in Figure 3. Figure 4 shows the layout for the setting of the nozzles for the MQL experiment. Horizontally, the nozzles were 120 degrees apart from each other, and the horizontal distance to the cutting tool is $6 \mathrm{~mm}$. The vertical distance from the nozzles to the surface of the workpiece is $4 \mathrm{~mm}$. 


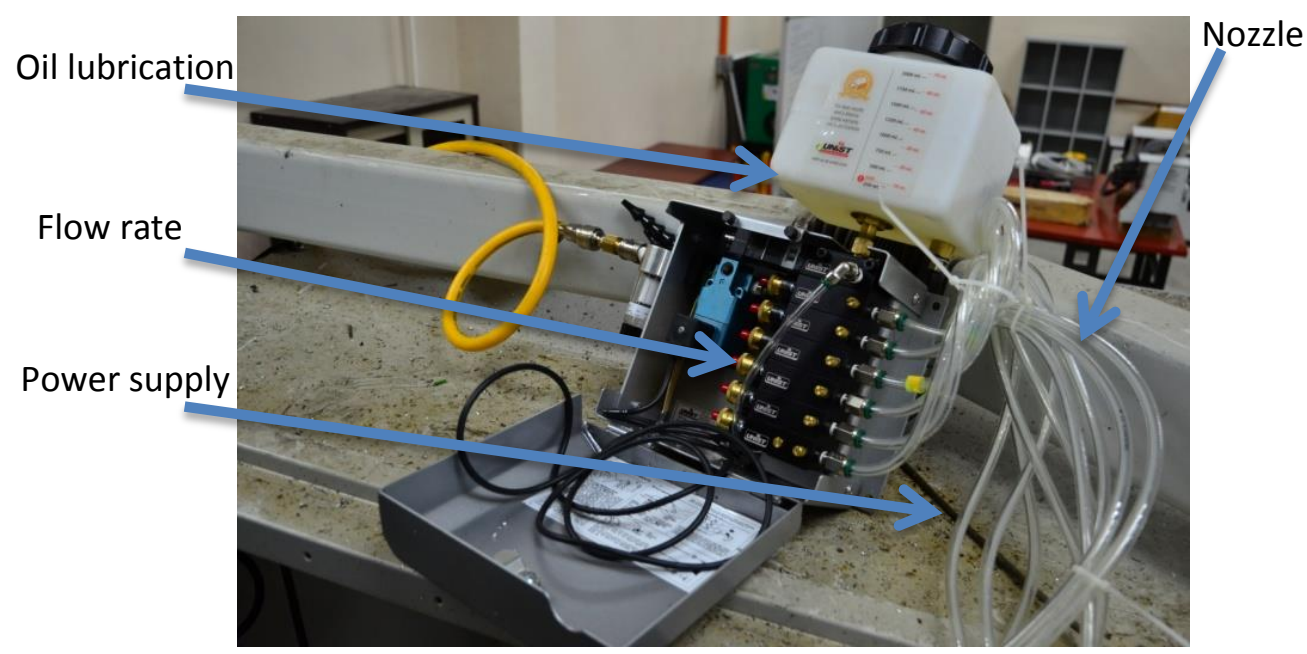

Figure 3. UNIST Coolube MQL supply.

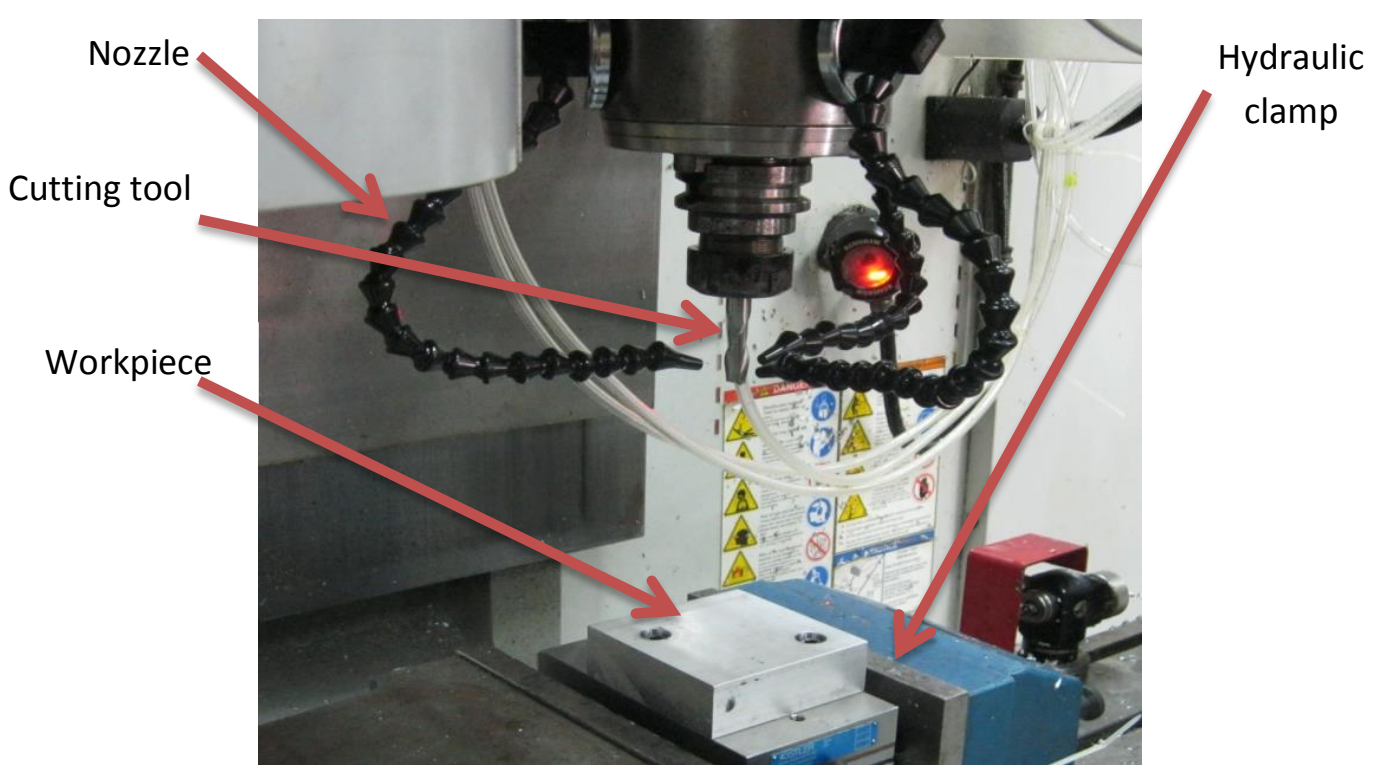

Figure 4. Nozzle configuration around the tool.

\section{RESULTS AND DISCUSSION}

The purpose of this study is to develop a mathematical model by making use of the response surface methodology. The mathematical model will help to establish the relationships between input variables like the feed rate, axial depth, cutting speed and MQL flow rate with the cutting response, which is surface roughness in this case. Table 3 shows the corresponding design of experiment for the two coated inserts. Along with the design of experiment, we can see the response parameters data of surface roughness for the inserts that has been obtained from the experiments in Table 4. A total of three nozzles were used for this experiment. Each nozzle generates a particular number of strokes per minute. The nozzle can be set by turning the valve through a number of turns. The flow rate setting specifications are shown in Table 5. 
Table 4. Measured values of average surface roughness under minimum quantity lubrication (MQL) conditions.

\begin{tabular}{cccccc}
\hline $\begin{array}{c}\text { Speed } \\
(\mathrm{RPM})\end{array}$ & $\begin{array}{c}\text { Feed rate } \\
(\mathrm{mm} / \mathrm{min})\end{array}$ & $\begin{array}{c}\text { Depth } \\
\text { of cut } \\
(\mathrm{mm})\end{array}$ & $\begin{array}{c}\text { MQL flow } \\
\text { rate }(\mathrm{ml} / \mathrm{min})\end{array}$ & $\begin{array}{c}\text { Surface } \\
\text { roughness }(\mu \mathrm{m})- \\
\text { TiAlN- coated } \\
\text { carbide }\end{array}$ & $\begin{array}{c}\text { Surface roughness } \\
(\mu \mathrm{m}) \text { - TiAlN+TiN- } \\
\text { coated carbide }\end{array}$ \\
\hline 5252 & 379 & 2.00 & 0.6525 & 0.562 & 0.532 \\
5300 & 318 & 1.00 & 0.48 & 0.845 & 0.202 \\
5300 & 318 & 1.00 & 0.825 & 0.486 & 0.464 \\
5300 & 318 & 3.00 & 0.48 & 1.034 & 0.580 \\
5300 & 318 & 3.00 & 0.825 & 0.875 & 0.853 \\
5300 & 440 & 1.00 & 0.48 & 1.017 & 0.222 \\
5300 & 440 & 1.00 & 0.825 & 0.516 & 0.309 \\
5300 & 440 & 3.00 & 0.48 & 1.175 & 0.690 \\
5300 & 440 & 3.00 & 0.825 & 0.563 & 0.558 \\
5400 & 288 & 2.00 & 0.6525 & 1.033 & 0.617 \\
5400 & 379 & 0.52 & 0.6525 & 0.212 & 0.350 \\
5400 & 379 & 2.00 & 0.39 & 1.505 & 0.804 \\
5400 & 379 & 2.00 & 0.6525 & 0.971 & 0.756 \\
5400 & 379 & 2.00 & 0.6525 & 1.091 & 0.772 \\
5400 & 379 & 2.00 & 0.9 & 0.803 & 0.695 \\
5400 & 379 & 3.48 & 0.6525 & 0.745 & 1.047 \\
5400 & 469 & 2.00 & 0.6525 & 1.132 & 0.717 \\
5500 & 318 & 1.00 & 0.48 & 0.749 & 0.442 \\
5500 & 318 & 1.00 & 0.825 & 0.623 & 0.524 \\
5500 & 318 & 3.00 & 0.48 & 0.819 & 0.629 \\
5500 & 318 & 3.00 & 0.825 & 1.098 & 0.575 \\
5500 & 440 & 1.00 & 0.48 & 1.346 & 0.976 \\
5500 & 440 & 1.00 & 0.825 & 0.606 & 0.921 \\
5500 & 440 & 3.00 & 0.48 & 1.496 & \\
5500 & 440 & 3.00 & 0.825 & 0.906 & 0.816 \\
5548 & 379 & 2.00 & 0.6525 & & \\
\hline
\end{tabular}

Table 5. MQL flow rate setting specification.

\begin{tabular}{cc}
\hline No. of valve turns & MQL flow rate, $\mathrm{ml} / \mathrm{min} /$ nozzle \\
\hline 2.4 & 0.013 \\
3 & 0.016 \\
4 & 0.022 \\
5 & 0.0275 \\
6 & 0.030 \\
\hline
\end{tabular}

\section{Regression Analysis}

Table 6 shows the estimated regression coefficients for ANOVA. The probability value should be less than 0.05 in order for it to be significant, while for the lack of fit value, it needs to be more than 0.05 to be significant. Table 6 shows that the model for surface roughness obtained from the TiAlN-coated insert contains four squared terms, four 
linear terms and six interaction terms. The overall regression for surface roughness obtained from the TiAlN+TiN-coated insert is significant with a p-value $0.000<0.05$. All the four squared terms (Speed x Speed; Feed rate x Feed rate; Depth of cut $x$ Depth of cut and MQL flow rate $\mathrm{x}$ MQL flow rate) show significance, i.e., the data obtained follows a curved trend. The linear term of feed rate and the interaction between feed rate and MQL flow rate also show significance. The overall regression shown in Table 6 with a p-value of 0.000 shows a quadratic surface for the surface roughness. The quadratic terms for feed rate and depth of cut are significant as per ANOVA. The linear terms of feed rate, depth of cut and MQL flow rate are significant. The interaction effects of speed with feed rate, depth of cut and MQL flow rate are also significant, i.e., the effects of speed, feed rate, depth of cut and MQL flow rate are not independent of each other. The interaction effect of feed rate with MQL flow rate is also significant.

Table 6. Estimated regression coefficients for surface roughness under minimum quantity lubrication (MQL) machining conditions.

\begin{tabular}{lcccc}
\hline Term & $\begin{array}{c}\text { Coefficient } \\
\text { TiAlN- coated } \\
\text { carbide }\end{array}$ & $\begin{array}{c}\text { p-value } \\
\text { TiAlN- coated } \\
\text { carbide }\end{array}$ & $\begin{array}{c}\text { Coefficient } \\
\text { TiAlN+TiN coated } \\
\text { carbide }\end{array}$ & $\begin{array}{c}\text { p-value } \\
\text { TiAlN+TiN } \\
\text { oated carbide }\end{array}$ \\
\hline Regression & - & 0.000 & - & 0.000 \\
Linear & - & 0.072 & - & 0.003 \\
Square & - & 0.001 & - & 0.031 \\
Interaction & - & 0.018 & - & 0.003 \\
Constant & -234.691 & 0.069 & -153.322 & 0.109 \\
Speed & 0.092397 & 0.054 & 0.054769 & 0.119 \\
Feed rate & -0.06537 & 0.043 & -0.04774 & 0.049 \\
Depth of cut & 0.182275 & 0.916 & 5.0673 & 0.002 \\
MQL flow rate & -11.03 & 0.288 & 22.67201 & 0.011 \\
Speed x Speed & -8.98 E-06 & 0.045 & $-5.08 \mathrm{E}-06$ & 0.118 \\
Feed rate x Feed rate & $2.40 \mathrm{E}-05$ & 0.046 & $-2.09 \mathrm{E}-05$ & 0.025 \\
Depth of cut x Depth & -0.18559 & 0.001 & -0.06349 & 0.058 \\
MQL flow rate x & 4.044785 & 0.012 & -1.32176 & 0.217 \\
Speed x Depth of cut & $1.06 \mathrm{E}-05$ & 0.060 & $1.28 \mathrm{E}-05$ & 0.006 \\
Speed x Feed rate & 0.000132 & 0.676 & -0.00082 & 0.005 \\
Speed x MQL flow & -0.001645 & 0.377 & -0.00337 & 0.030 \\
Feed rate x Depth of & -0.00048 & 0.363 & -0.00036 & 0.361 \\
Feed rate x MQL flo & -0.01234 & 0.001 & -0.0064 & 0.015 \\
Depth of cut x MQL & 0.233333 & 0.218 & -0.1721 & 0.229 \\
\hline
\end{tabular}

The quality of a product is scrutinized by its surface roughness because this is a fundamental quality feature of an end milled product. If a higher surface finish is required, it is essential that before the process starts the setting of cutting parameters is done properly $[20,21]$. The mechanical properties of the workpieces that have to be machined, the rotational speed of the cutter, velocity of traverse and feed rate are all factors that yield the final surface, but the machining process is responsible for the development of surface roughness [22]. RSM has been used to develop the second order mathematical models. Equation (1) presents the second-order model: 


$$
\begin{aligned}
& y^{\prime \prime}=\beta_{0} x_{0}+\beta_{1} x_{1}+\beta_{2} x_{2}+\beta_{3} x_{3}+\beta_{11} x^{2}{ }_{1}+\beta_{22} x^{2}{ }_{2}+\beta_{33} x^{2}{ }_{3} \\
& +\beta_{11} x_{1} x_{2}+\beta_{12} x_{1} x_{3}+\beta_{13} x_{2} x_{3}
\end{aligned}
$$

The surface roughness for the TiAIN-coated inserts for MQL is represented by Eq. (2):

$$
\begin{gathered}
R_{a}=-234.691+0.092397 x_{1}-0.06537 x_{2}+0.182275 x_{3}-11.03 x_{4} \\
+0.0000106 x_{1} x_{2}+0.000132 x_{1} x_{3}-0.001645 x_{1} x_{4}-0.00048 x_{2} x_{3} \\
-0.01234 x_{2} x_{4}+0.233333 x_{3} x_{4}-8.98 \times 10^{-6} x_{1}{ }^{2} \\
+2.40 \times 10^{-5} x_{2}{ }^{2}-0.18559 x_{3}{ }^{2}+4.044785 x_{4}{ }^{2}
\end{gathered}
$$

$\mathrm{R}^{2}$-value $=93.12 \% ;$ lack-of-fit $=0.482$

The surface roughness for the TiAlN+TiN-coated inserts for MQL is represented by Eq. (3):

$$
\begin{aligned}
& R_{a}=-153.322+0.054769 x_{1}-0.04774 x_{2}+5.0673 x_{3}+22.67201 x_{4} \\
& +0.0000128 x_{1} x_{2}-0.00082 x_{1} x_{3}-0.00337 x_{1} x_{4}-0.00036 x_{2} x_{3} \\
& -0.0064 x_{2} x_{4}-0.1721 x_{3} x_{4}-5.08 \times 10^{-6} x_{1}^{2} \\
& -2.09 \times 10^{-5} x_{2}{ }^{2}-0.06349 x_{3}^{2}-1.32176 x_{4}^{2}
\end{aligned}
$$

$\mathrm{R}^{2}$-value $=91.77 \% ;$ lack-of-fit $=0.09$.

where

$$
\begin{array}{ll}
x_{1}=\text { spindle speed, } \mathrm{rpm} & x_{2}=\text { feed } \mathrm{rate}, \mathrm{mm} / \mathrm{min} \\
x_{3}=\text { depth of cut }, \mathrm{mm} & x_{4}=M Q L \text { flow } \mathrm{rate}, \mathrm{ml} / \mathrm{min}
\end{array}
$$

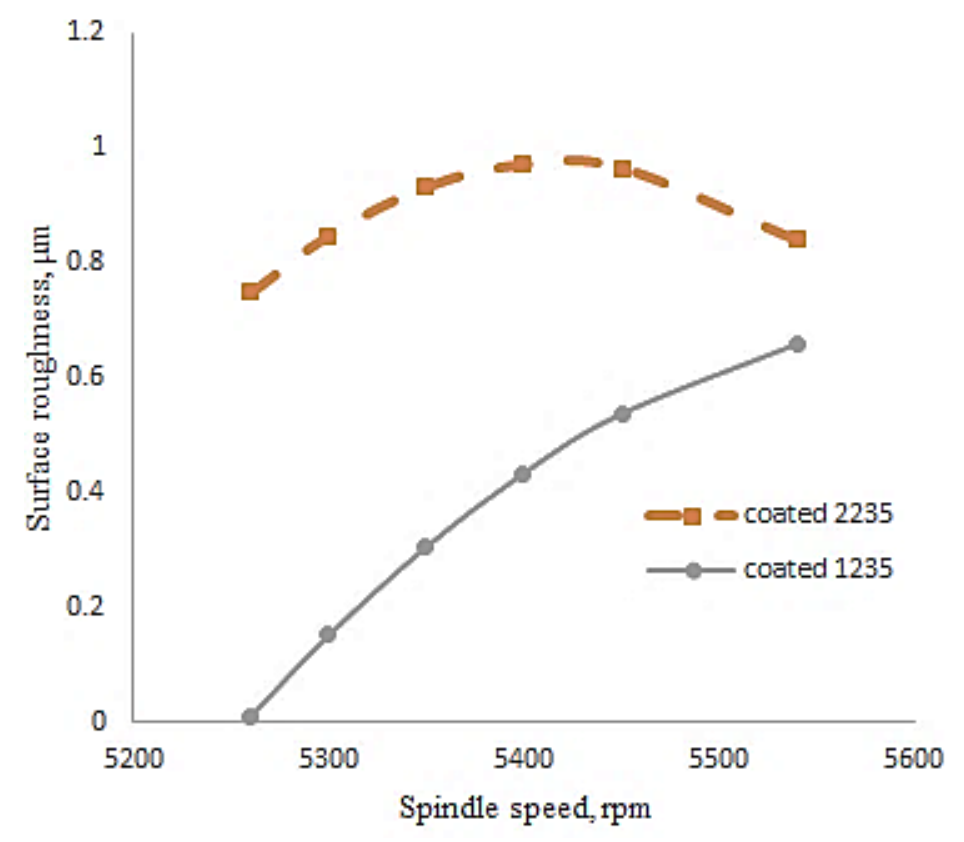

Figure 5. Surface roughness versus spindle speed. 


\section{Analysis of Surface Roughness}

Figure 5 shows the surface roughness versus spindle speed for the TiAlN-coated carbide insert. It can be seen that surface roughness increases linearly with increase of the spindle speed until $5450 \mathrm{rpm}$, then decreases accordingly. For the TiAlN+TiN-coated carbide insert an increasing pattern is seen, but the surface roughness values are much lower than those obtained for the TiAlN-coated insert. Figure 6 shows the relationship between surface roughness and depth of cut. The surface roughness follows the same pattern as with spindle speed. Figure 7 illustrates the relationship between surface roughness and feed rate. For the TiAlN-coated carbide insert, surface roughness shows an increasing trend with increasing feed rate. For the TiAlN+TiN-coated carbide insert, surface roughness increases with increasing feed rate and after a certain feed rate it starts to decrease.

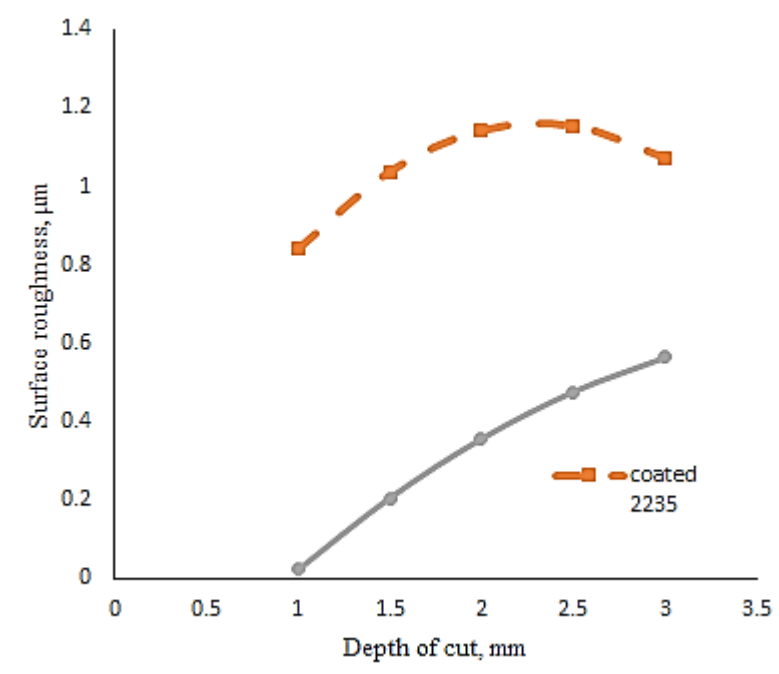

Figure 6. Surface roughness versus depth of cut.

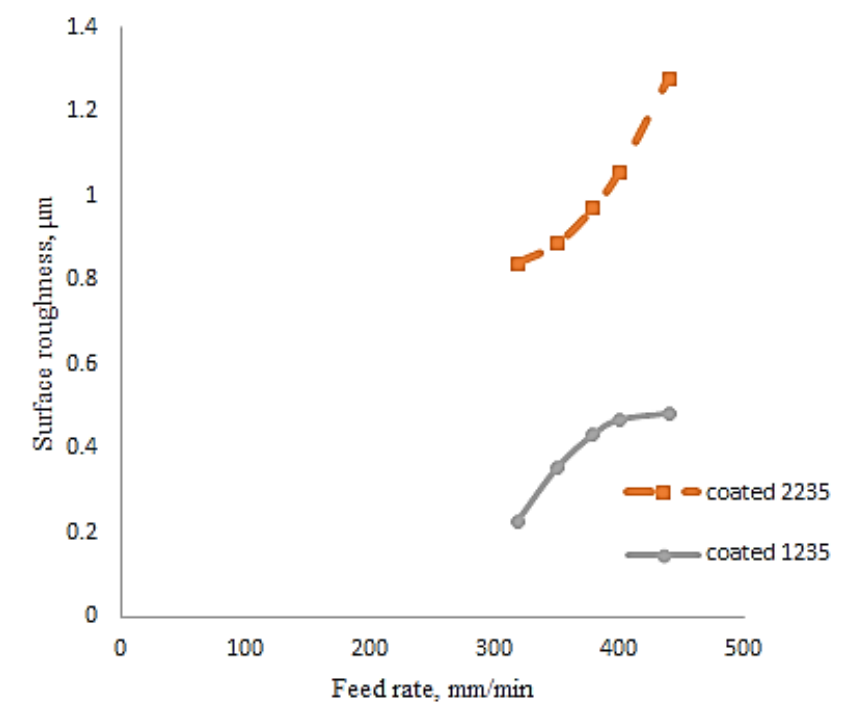

Figure 7. Surface roughness versus feed rate (coated 2235=TiAlN-coated; coated 1235=TiAlN+TiN-coated insert). 


\section{Microstructure Analysis}

Figure 8 shows the microstructure from the experiments of TiAlN-coated carbide with the flooded condition. As can be seen, the surfaces are marked with what appear to be linear lines. For workpiece A with the MQL condition, the surface seems to be rather rough compared to the one with the flooded condition. It is to be understood that the greater strength of nickel-based alloys is due to elevated temperature, high ductility, high tendency to work hardening, etc., which is why heat treatment strengthens them further because of their sensitivity to microstructure change [23]. As can be seen, the surfaces of the workpiece with MQL are marked with what appear to be spots whilst maintaining the linear pattern. For the flooded condition, the pattern seems to be more uniformly linear-lined compared to the workpiece with the MQL condition. [24] stated that the materials and cutting conditions and the depth of cut cannot influence the surface roughness. The reported thermal and mechanical cycling, microstructural transformations, and mechanical and thermal deformations during the machining processes all cause these impacts [25]. The functional characteristics of products including their fatigue, friction, wear, light reflection, heat transmission, and lubrication will all affect the surface roughness [26]. When the product is exposed to extensive machining, we may observe slight differences in the surface roughness because of the on-going wear produced at the coated carbide cutting edge and the temperature reduction at the cutting by the coolant, which is active all through the machining of Inconel 718 [27]. Hence, we can see the significance of lubrication in end milling machining.

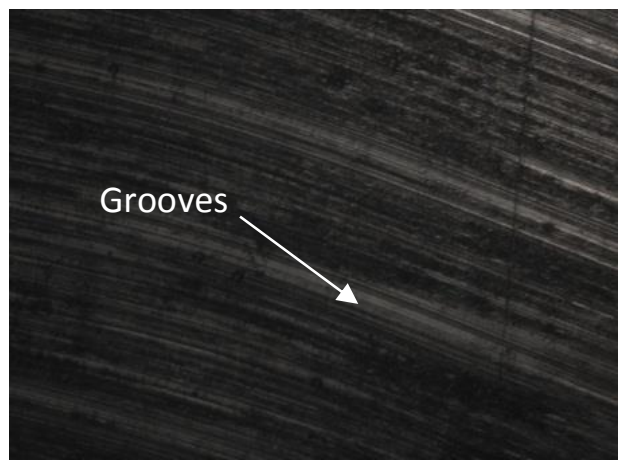

(a)

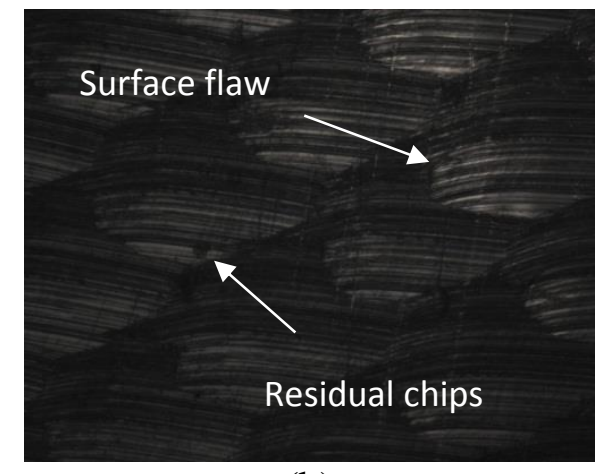

(b)

Figure 8. Microstructure of coated carbide 2235 with workpiece A: (a) flooded condition; (b) MQL condition.

\section{CONCLUSIONS}

An experimental investigation of coated carbide cutting tool performance on the surface roughness of aluminum alloy $6061 \mathrm{~T} 6$ when machining with end mill processes using the minimum quantity lubrication technique has been performed. Analysis of variance is utilized to validate the experimental data to check its adequacy. The response surface method was used to develop the mathematical modeling and to optimize the machining parameters when machining aluminum alloy 6061-T6 using coated carbide (CTP 2235) and coated carbide (CTP 1235). Second-order models were developed based on the surface roughness results. According to this result, higher depth of cut, higher spindle speed, lower feed rate and less lubrication may produce a bad surface finish. Besides, 
differences in the feed rate and spindle speed range could cause different types of pattern in the surface finish. Flooded machining and minimum quantity lubrication show different values of surface roughness and surface finish patterns. The performance of the TiAlN+TiN-coated tool is better in terms of surface roughness and roughness texture. Hence MQL can easily be employed for the end milling of aluminum alloy, providing acceptable surface quality as well as imparting economic benefits in terms of reduced lubricant costs and better machinability.

\section{ACKNOWLEDGEMENTS}

The authors would like to acknowledgements Ministry of Education Malaysia and Universiti Malaysia Pahang for providing laboratory facilities and financial support under project no. RDU110110.

\section{REFERENCES}

[1] Najiha MS, Rahman MM, Yusoff AR, Kadirgama K. Investigation of flow behavior in minimum quantity lubrication nozzle for end milling processes. International Journal of Automotive and Mechanical Engineering. 2012;6:76876.

[2] Puvanesan M, Rahman MM, Najiha MS, Kadirgama K. Experimental investigation of minimum quantity lubrication on tool wear in aluminum alloy 6061-t6 using different cutting tools. International Journal of Automotive and Mechanical Engineering. 2014;9:1538-49.

[3] Najiha MS, Rahman MM, Kamal M, Yusoff AR, Kadirgama K. Minimum quantity lubricant flow analysis in end milling processes: A computational fluid dynamics approach. Journal of Mechanical Engineering and Sciences. 2012;3:340-5.

[4] Weinert K, Inasaki I, Sutherland JW, Wakabayashi T. Dry machining and minimum quantity lubrication. CIRP Annals - Manufacturing Technology. 2004;53:511-37.

[5] Marksberry PW, Jawahir IS. A comprehensive tool-wear/tool-life performance model in the evaluation of NDM (near dry machining) for sustainable manufacturing. . International Journal of Machine Tools and Manufacture. 2008;48:878-86.

[6] Shao G, Kibira D, Lyons K. A virtual machining model for sustainability analysis. In: Manufacturing Systems Integration Division National Institute of Standards and Technology Gaithersburg M, editor. Proceedings of ASME 2010 International Design Engineering Technical Conference \& Computers and Information in Engineering Conference, ASME CIE 2010. Montreal, Quebec, Canada2010.

[7] Chattopadhyay AK, Roy P, Ghosh A, Sarangi SK. Wettability and machinability study of pure aluminium towards uncoated and coated carbide cutting tool inserts. Surface and Coatings Technology. 2009;203:941-51.

[8] Sreejith PS. Machining of 6061 aluminium alloy with MQL, dry and flooded lubricant conditions. Materials Letters. 2008;62:276-8.

[9] Lacalle LNLd, Lamikiz A, Sanchez JA, Cabanes I. Cutting conditions and tool optimization in the high-speed milling of aluminium alloys. Part B: Journal of Engineering Manufacture. 2001;215:1257-69. 
[10] Macmaster FJ, Chan KS, Bergsma SC, Kassner ME. Aluminum alloy 6069 part II fracture toughness of 6061-T6 and 6069-T6. Materials Science and Engineering: A. 2000;289:54-9.

[11] Chu E, $\mathrm{Xu} \mathrm{Y}$. Hydroforming of aluminum extrusion tubes for automotive applications. Part 1: buckling, wringkling and bursting analyses of aluminum tubes. International Journal Mechanical Science. 2004;46:263-83.

[12] Ghani JA, Choudhury IA, Masjuki HH. Wear mechanism of TiN coated carbide and uncoated Cermets tools at high cutting speed applications. Journal of Materials Processing Technology. 2004;153-154:1067-73.

[13] Rajakumar S, Muralidharan C, Balasubramanian V. Predicting tensile strength, hardness and corrosion rate of friction stir welded AA6061-T6 aluminium alloy joints. Materials \& Design. 2011;32:2878-90.

[14] Xu X, Yang X, Zhou G, Tong J. Microstructures and fatigue properties of friction stir lap welds in aluminum alloy AA6061-T6. Materials \& Design. 2012;35:175-83.

[15] Zhang H, Wu Q, Lin J, Chen J, 124304. ZXAP. Thermal conductivity of polyethylene glycol nanofluids containing carbon coated metal nanoparticles. Journal of Applied Physics. 2010;108:124304-9.

[16] Zhang MZ, Liu YB, Zhou H. Wear mechanism maps of uncoated HSS tools drilling die-cast aluminum alloy. Tribology International. 2001;34:727-31.

[17] Najiha MS, Rahman MM, Yusoff AR. Modeling of the end milling process for aluminum alloy AA6061t6 using HSS tool. International Journal of Automotive and Mechanical Engineering. 2013;8:1140-50.

[18] Razak NH, Rahman MM, Kadirgama K. Experimental study on surface integrity in end milling of hastelloy C-2000 superalloy. International Journal of Automotive and Mechanical Engineering. 2014;9:1578-87.

[19] Dhar NR, Kamruzzaman M, Ahmed M. Effect of minimum quantity lubrication (MQL) on tool wear and surface roughness in turning AISI-4340 steel. Journal of Materials Processing Technology. 2006;172:299-304.

[20] Khan MAR, Rahman MM, Kadirgama K. Mathematical model and optimization of surface roughness during electrical discharge machining of Ti-5Al-2.5Sn with graphite electrode. Advanced Science Letters. 2012;15:367-72.

[21] Rahman Khan MA, Rahman MM, Kadirgama K, Ismail AR. Mathematical model for wear rate of negative graphite electrode in electrical discharge machining on Ti-5A1-2.5Sn. Jurnal Teknologi (Sciences and Engineering). 2012;59:55-9.

[22] Benardos PG, Vosniakos GC. Predicting surface roughness in machining: a review. International Journal of Machine Tools and Manufacturing. 2003;43:833-44.

[23] Dudzinski D, Devillez A, Moufki A, Larrouquere D, Zerrouki V, Vigneau J. A review of developments towards dry and high speed machining of Inconel 718 alloy. International Journal of Machine Tools and Manufacture. 2004;44: 43956.

[24] Ginting A, Nouari M. Surface integrity of dry machined titanium alloys. International Journal of Machine Tools and Manufacture. 2009;49:325-32.

[25] Axinte DA, Dewes RC. Surface integrity of hot work tool steel after high speed milling-experimental data and empirical models. Journal of Materials Processing Technology. 2002;127:325-33. 
[26] Ibraheem AF, Shather SK, 1-4. KAKET. Prediction of cutting forces by using mMachine parameters in end milling process. Engineering \& Technology. 2008;26:1-4.

[27] Ezugwu E, Bonney J, Olajire K. The effect of coolant concentration on the machinability of nickel-base, nimonic C-263, alloy. Tribology Letters. 2004;16:311-6. 